\title{
Synthesis of Polypyrrole-Coated Core/Shell Nanoparticles
}

\author{
Andreas Mühlebachª Andreas Hafnerª, François Rimea ${ }^{\star}$, Konstantinos Mpoukouvalas ${ }^{\mathrm{b}}$, Ling \\ Sun ${ }^{\mathrm{b}}$, Jianjun Wang ${ }^{\mathrm{b}}$, Gerhard Wegner ${ }^{\mathrm{b}}$, and Tilman Beierlein ${ }^{\mathrm{c}}$
}

\begin{abstract}
Dedicated to Prof. Dr. Daniel Belluš on the occasion of his 70th birthday
Abstract: The synthesis, physical characterization and scale-up of conductive, re-dispersible core/shell nanoparticles containing polypyrrole (PPy) in the shell are described. The compressed powders/films show a DC conductivity which is considerably higher than that of commercial standard products based on PEDOT/PSS ('AL 4083' from H.C. Starck). The particles have excellent film-forming properties since thin films (50-100 nm) made by spin-coating from aqueous dispersions of the particles have an AFM film roughness of $<15 \mathrm{~nm}$ even before annealing. The materials were tested as hole injection/smoothening layers in fluorescent OLED devices, and are in a comparable range to PEDOT/PSS-based materials in respect to performance (film forming, luminance, efficiency, and lifetime).
\end{abstract}

Keywords: Conductive polymers · Core/shell nanoparticles · Organic electronics · Polypyrrole · Spherical polyelectrolyte brush

\section{Introduction}

Ciba Inc. but also BASF have, for many years, maintained strong activity in the area of printed organic electronics. In this context, Ciba's Group Research and the Max Plank Institute for Polymer Research in Mainz have closely worked together to develop new types of printable conductive nano-particles. Polypyrrole (PPy) was chosen as conductive layer since it is was one of the first conductive polymers reported in literature ${ }^{11]}$ and has been investigated for many years within the former Central Research unit of Ciba-Geigy. ${ }^{[2]}$ However, brittleness and lack of processability prevented its successful application in plastic electronics. In order to circumvent this problem, the goal of this work was to synthesize composite nanoparticles with a soft polymer core and an anionic polypyrrole (PPy) containing shell.

\footnotetext{
${ }^{*}$ Correspondence: Dr. A. Mühlebach ${ }^{a}$ Tel.: +41616362427

E-mail: andreas.muehlebach@ciba.com Dr.: A. Hafnera

Tel.: +41616365437

E-mail: andreas.hafner@ciba.com

${ }^{a} \mathrm{C} i b a$ Inc. (now part of BASF)

Performance Chemicals Research

Klybeckstrasse 141

$\mathrm{CH}-4002$ Basel

bMax Planck Institute for Polymer Research

Ackermannweg 10

D-55128 Mainz, Germany

'CSEM - Centre Suisse d'Electronique et

de Microtechnique SA

Mattenstrasse 22

$\mathrm{CH}-4058$ Basel
}

Latex particles coated by conducting polymers were first reported in 1987,[3] and this approach has found widespread attention. The idea was to create a core of a thermoplastic polymer which would undergo film formation as in typical surfactant-stabilized lattices by coalescence under the action of heat and/or induced by solvent swelling. The conducting polymers placed at the surface of the individual particles would then become dispersed in these films where they form an electrical percolating structure given that their volume concentration and morphology had been appropriately optimized. The transparency of the films would mainly depend on the total film thickness and the volume concentration of the conducting polymers with a wavelength-dependent absorptivity. In other words the conducting polymer acts like a pigment in the film and the core polymer as the matrix material. The process of film formation is irreversible and the initial individual particles have lost their identity in the final film.

To our knowledge, the application of latex particles for the construction of organic electronic devices (printed electronics) has not been investigated so far beside our own work. ${ }^{[4,5]}$ The small size $(<100 \mathrm{~nm})$ and re-dispersibility (in water and organic solvents commonly used for printing inks) of such core/shell particles are important factors for applications in advanced technologies like plastic electronics. Therefore, we designed a new type of conductive core/ shell nano-particles with a structure to be amenable for manufacture processes common for polymer electronics: A core of a thermoplastic non-conducting polymer is surrounded by a corona of a polyelectrolyte, in this case a styrene sulfonate copolymer. This corona serves as the matrix in which domains of a conducting polymer are embedded via oxidative polymerization of the corresponding monomer. In this work we used pyrrole, however other monomers like thiophene derivatives could also be applied. In contrast to the commercially available PEDOT/PSS gel particle dispersions, where PEDOT is somehow deposited on a random coil PSS structure, the polyelectrolyte corona serves here as template for the oxidative polymerization of pyrrole to define the shape and size of the conducting polymer shell on the particles. It is also important to point out that the PSS chains attached onto the core particle surface are by purpose not fully consumed in complexing/neutralizing the cationic PPy. Rather, a sufficient fraction remains and - together with additional comonomers like M-PEG-acrylates - serve to electrosterically stabilize the individual colloidal particles. As a consequence, a material results which can be brought to dryness and afterwards can easily be redispersed to give an aqueous suspension of individual nanoparticles. Inks can be formulated quite easily and spin-coated or printed to make thin films useful in the assembly of optoelectronic devices and displays. If the particles are small and the volume fraction of the conductive polymer is high enough, an electrical percolating shell should be formed upon annealing, leading to the formation of transparent conducting films. 


\section{Experimental}

\subsection{Materials and Instruments}

Solvents, reagents and monomers are all commercially available (Aldrich, Fluka and Acros) and were used as received, except for pyrrole (Py), which was distilled before reaction. The poly(ethylene glycol) methylether acrylate (M-PEG-A from Aldrich) had a number average molecular weight $\left(\mathrm{M}_{\mathrm{n}}\right)$ of $454 \mathrm{~g} / \mathrm{mol}$.

The particle size and film quality were checked by tapping mode atomic force microscopy (AFM), dimension 3100 close loop (Digital instrument Veeco metrology group). TEM was carried out on a LEO EM 912 with $1 \mathrm{~K}$ CCD camera. Vis-NIR spectra were measured with a Lambda UV/ VIS/NIR- \& UV/VIS Spectrometer (Perkin-Elmer). The dynamic light scattering measurements (DLS) were performed on a light scattering line with an ALV 5000 correlator (ALV, Langen), an ALV-SP81 goniometer, an avalanche photodiode and a krypton ion laser $(647.1 \mathrm{~nm})$. Ultrafiltration (UF) was done either in Amicon ${ }^{\circledR}$ or VivaFlow ${ }^{\circledR}$ cells with polyethersulfone membranes (cut-off values as specified). Thermogravimetric analyses (TGA) and differential scanning calorimetry (DSC) were performed under air on Mettler Toledo TC15 TA and Mettler Toledo DSC30 instruments and controllers with a heating rate of $10^{\circ} \mathrm{C} / \mathrm{min}$ in both cases. Elemental analyses were obtained from the Ciba Service Center Elemental Analysis.

\subsection{Conductivity Measurements with the Four-point Method}

Specimens with the dimensions $30 \times 5$ $\times(0.4-1) \mathrm{mm}$ were prepared by compressing the freeze-dried powders in a mould with a load of $6 \mathrm{t}$ ( $\mathrm{p} c a .4000$ bar). A current of 50 or $100 \mathrm{~mA}$ was applied (two outer electrodes) and the voltage drop measured on the two inner electrodes.

\subsection{Conductivity Measurements by Impedance Spectroscopy (IS)}

The sample cell consisted of two electrodes with $10 \mathrm{~mm}$ diameter, surrounding the sample pellet with a thickness of 800 $\mu \mathrm{m}$ (made in the same way as above). The dielectric measurements were carried out at temperatures between 183 and $453 \mathrm{~K}$ at ambient pressure. The temperature was controlled by a Novocontrol Quatro Cryosystem, using $\mathrm{N}_{2}$ to heat and cool the sample with an accuracy of $0.1 \mathrm{~K}$. The frequencies sensed by a Novocontrol Alpha Analyzer in the range of $10^{-2}$ to $10^{6} \mathrm{~Hz}$.

\subsection{Film Roughness Measurements by AFM and Kelvin Probe Force Microscopy (KPFM)}

Films were prepared by spin-coating using the spin coater of Headway Research

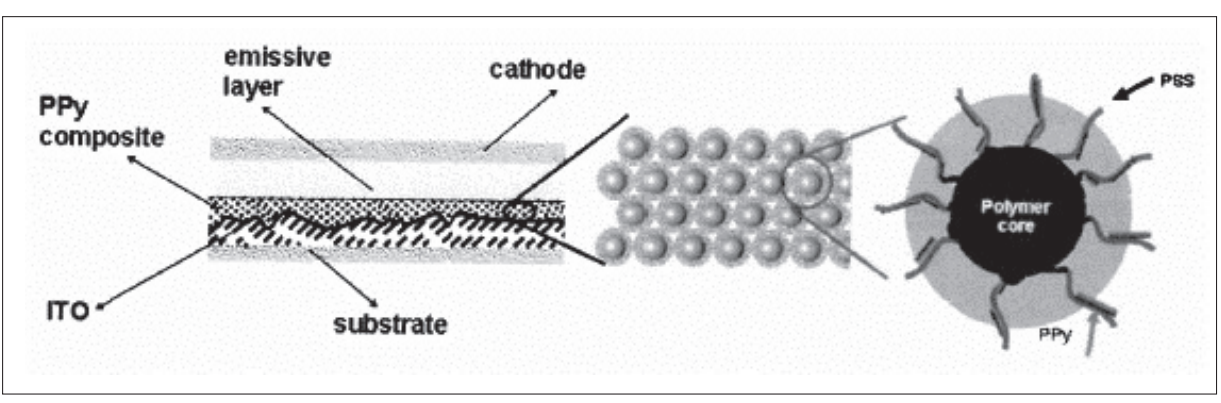

Fig. 1. Schematic drawing of the OLED devices prepared with AL 4083 and CP1-CP3.

Inc. The particle concentration was about $2 \%(\mathrm{w} / \mathrm{w})$. The spin speed was adjusted to obtain a desired film thickness, which was measured by a TENCOR ${ }^{\circledR}$ P-10 surface profiler. The surface quality of these colloidal films was checked by tapping mode atomic force microscopy (AFM), Dimension 3100 close loop (see above).

\subsection{Preparation of Light-emitting Devices (OLEDs)}

Glass substrates with patterned ITO were cleaned with acetone, 1-propanol and water in an ultrasonic bath. The dried substrates were treated with oxygen plasma for $2 \mathrm{~min}$. The dispersion with 2-3\% solid content was spin-coated ( $c a .5000$ rpm) to obtain a film thickness of $c a$. 70 $\mathrm{nm}$. A reference sample was prepared in analogous manner (1500 rpm, $70 \mathrm{~nm}$ ) but using PEDOT/PSS 'AL 4083' (supplier: H.C. Starck) instead of the present compound. The films were dried and annealed on a hot plate at $180-200{ }^{\circ} \mathrm{C}$ for $10 \mathrm{~min}$ in ambient atmosphere. Under nitrogen, the blue-emitting dye Super Yellow (SY from Merck) was spin-coated on top with a layer thickness of $80 \mathrm{~nm}$ (= emissive layer). The devices were finished by evaporation of a bilayer cathode consisting of $5 \mathrm{~nm} \mathrm{Ba}$ and $70 \mathrm{~nm} \mathrm{Al}$. A schematic drawing of the OLED device is shown in Fig. 1. Device characterization was carried out under inert atmosphere and results are shown in Table 1 and discussed later.

\subsection{Synthesis of the Core Particles P1}

Sodiumdodecylsulfate (SDS, $5 \mathrm{~g}$ ) and water $(500 \mathrm{ml})$ were introduced in a 11 round bottom flask with mechanical stirring, and purged with nitrogen during 15 min. After heating to $55^{\circ} \mathrm{C}$ with an oil bath, a first portion of potassiumperoxodisulfate (KPS, $0.25 \mathrm{~g}$ ), dissolved in water $(6 \mathrm{ml})$ was added. The monomer mixture consisting of styrene $(21 \mathrm{~g}, 201.6 \mathrm{mmol})$, n-butyl acrylate $(25 \mathrm{~g}, 195.1 \mathrm{mmol})$ and allyl-methacrylate $(4.0 \mathrm{~g}, 31.7 \mathrm{mmol})$ was added slowly during $8 \mathrm{~h}$ while maintaining the emulsion at $55^{\circ} \mathrm{C}$ and the stirring speed at $300 \mathrm{rpm} .3 \mathrm{~h}$ after the start of the mono- mer addition, a second portion of KPS $(0.25 \mathrm{~g})$, dissolved in water $(6 \mathrm{ml})$ was added. The reaction mixture was heated for $14 \mathrm{~h}$ at $55^{\circ} \mathrm{C}$ and then cooled to r.t. $576.6 \mathrm{~g}$ of white latex was obtained with solid content of $7.25 \%$, measured by graphimetric analysis of a dried sample.

Diameter: $\mathrm{d}=28.4 \mathrm{~nm}$ (z-average from DLS); $d=30 \mathrm{~nm}$ (TEM). $\mathrm{T}_{\mathrm{g}}=30^{\circ} \mathrm{C}(\mathrm{DSC}$ of freeze-dried product).

\subsection{Synthesis of the Core/shell Nanoparticles P2 (Slightly Cross- linked Poly(sodium 4-vinylbenzene sulfonate/PEG-acrylate) as First Shell or 'Corona')}

In a 11 round bottom flask with mechanical stirring, $41.4 \mathrm{~g}$ of the core particles dispersion $\mathbf{P 1}$, corresponding to $3 \mathrm{~g}$ solid material, was diluted with water $(200 \mathrm{ml})$ and purged with nitrogen during $2 \mathrm{~h}$. The mixture was stirred at $300 \mathrm{rpm}$ under $\mathrm{N}_{2}$ and heated with an oil bath to $70{ }^{\circ} \mathrm{C}$. p-Divinylbenzene (1.5 g, $11.5 \mathrm{mmol})$, n-butyl acrylate $(1.5 \mathrm{~g}$, $11.7 \mathrm{mmol}$ ) and KPS (40 mg), dissolved in water $(3 \mathrm{ml})$ were added subsequently with a syringe through a septum. The mixture was stirred at $70{ }^{\circ} \mathrm{C}$ for $30 \mathrm{~min}$. Two monomer solutions were prepared:

A) A mixture of 4-vinylbenzene-sulfonic acid sodium salt $(20.61 \mathrm{~g}, 90 \mathrm{mmol})$ and ethylene-glycol dimethacrylate (EDMA, $0.18 \mathrm{~g}, 0.95 \mathrm{mmol})$ in water $(100 \mathrm{ml})$

B) A mixture of 2-ethoxyethyl methacrylate (EEMA, $6.67 \mathrm{~g}, 42.2 \mathrm{mmol}$ ), ethylene-glycol dimethacrylate (EDMA, 0.18 $\mathrm{g}, 0.95 \mathrm{mmol})$ and poly(ethylene glycol) methylether acrylate (M-PEG-A, $6.67 \mathrm{~g}$, $14.7 \mathrm{mmol}$ ).

A solution of KPS $(80 \mathrm{mg})$ dissolved in water $(6 \mathrm{ml})$ was added to the original reaction mixture (temperature at $70{ }^{\circ} \mathrm{C}$ ) followed by continuous addition of the solutions A) and B) with two separate pumps during $4 \mathrm{~h}$. After the addition of all monomers, another portion of KPS (40 mg) dissolved in water $(3 \mathrm{ml})$ was added and the reaction continued at $95^{\circ} \mathrm{C}$ overnight (post reaction).

After cooling to r.t., $444.4 \mathrm{~g}$ of white latex was obtained. One third of this amount was ultra-filtrated in a Amicon ${ }^{\circledR}$ cell with a polyethersulfone membrane 
Table 1. Characterisation of OLED devices made from core/shell nanoparticle dispersions (2-3\%) of CP1 and CP2 as hole injection layers, compared with PEDOT/PSS (AL 4083). First column: IV-curves: Left (upper curve): Current density [A/cm²]; right (lower curve): Luminance $\left[\mathrm{cd} / \mathrm{m}^{2}\right]$; horizontal axis: Voltage [V]. Second column: Y-axis: Efficiency [cd/A]; x-axis: Luminance [cd/m²]. Third column: Left (lower curve): Normalized luminance; right (upper curve): Normalized voltage; $x$-axis: Time [h].

Material

IV-curve

CP1

CP2

AL 4083
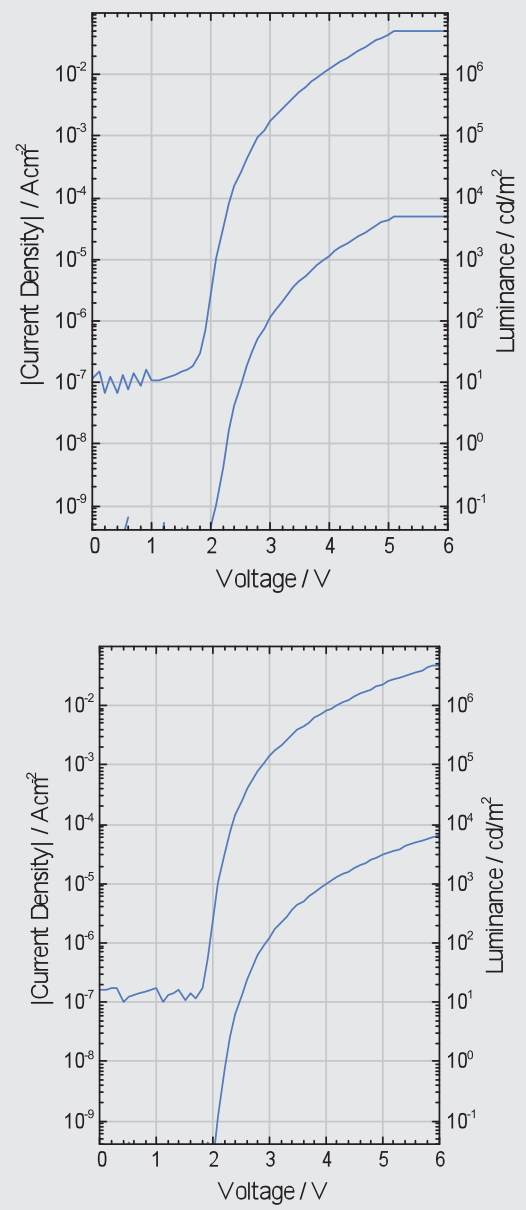

Efficiency

Lifetime
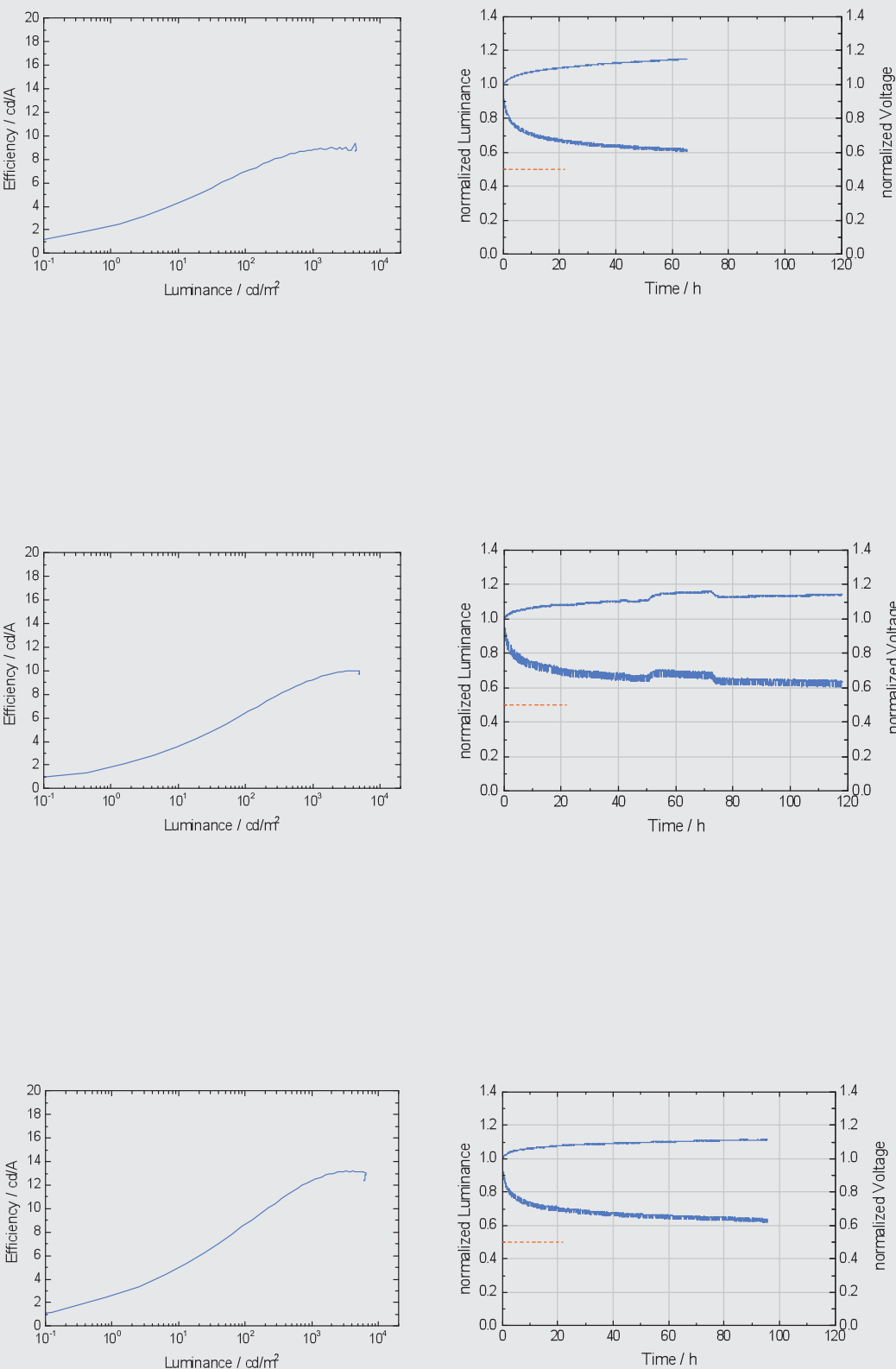

(diameter 76 mm, cut-off: 300'000 Da, $\mathrm{p}=5$ bar) until a total permeate quantity of $500 \mathrm{ml}$ was reached. The purified dispersion was then freeze-dried and 11.47 g solid powder obtained. Therefore, the solid content of the dispersion was calculated to be $7.7 \mathrm{wt} \%$, yielding a total solid content of $34.4 \mathrm{~g}$ for the "white latex'. The total monomer conversion was calculated to be $88 \%$. $\mathrm{d}=40 \mathrm{~nm}$ (average particle diameter in TEM for native dispersion). Sulfur content of freeze-dried material (elemental analysis): $6.89 \%$ (calc. $7.13 \%$ ).

\subsection{Synthesis of Polypyrrole (PPy)- coated Core/shell Nanoparticles CP1 (PPy Content: 23\%)}

In a $750 \mathrm{ml}$ round bottom flask with mechanical stirring $65.5 \mathrm{~g}$ of the core shell particle dispersion of $\mathbf{P 2}$, corresponding to $5.04 \mathrm{~g}$ solid material, was diluted with water $(250 \mathrm{ml})$ and degassed by purging with Ar for $1 \mathrm{~h}$. Pyrrole (1.81 g, $27 \mathrm{mmol})$ was added and the mixture stirred with 300 rpm under Ar at r.t. Iron(III)tosylate-hexahydrate $(42.07 \mathrm{~g}, 62.1 \mathrm{mmol})$ dissolved in water $(175 \mathrm{ml})$, degassed and purged with Ar before use, was then continuously added during $30 \mathrm{~min}$ with a pump. Thereafter, 
the reaction mixture was kept under Ar and stirred for another $2 \mathrm{~h}$ at r.t. Purification and work-up was done in three steps:

i) Ultrafiltration (UF): Two VivaFlow ${ }^{\circledR}$ cells with polyethersulfone membranes (cut-off: 100'000 Da), total permeate quantity: $3 \times 800 \mathrm{ml}$. ii) Removal of iron salts: Oxidation of all $\mathrm{Fe}(\mathrm{II})$ to $\mathrm{Fe}(\mathrm{III})$ by addition of $\mathrm{H}_{2} \mathrm{O}_{2}(30 \%, 0.92 \mathrm{~g})$ diluted in water $(10 \mathrm{ml})$, stirring for $1 \mathrm{~h}$ at r.t. followed by the addition of a $0.1 \mathrm{M}$ solution of ethylenediamine-tetraacetic acid disodium salt dihydrate (EDTA, $54.2 \mathrm{ml}$ ), stirring for 45 min and UF in two VivaFlow ${ }^{\circledR}$ cells with cellulose membranes (cut-off: 100'000 Da), total permeate quantity: $3 \times 800 \mathrm{ml}$. iii) Ion exchange (to remove sodium salt): The above dispersion was diluted with water by $50 \%$. The ion exchange was done on a column filled with acidic $\left(\mathrm{H}^{+}\right)$Amberlite $120 \mathrm{resin}(100 \mathrm{ml})$, at a flow of $2 \mathrm{ml} / \mathrm{min}$, followed by re-concentration of the dispersion by UF to a solid content of $5.6 \%$. A sample was freeze-dried for analysis:

Elemental analysis; found \% (calc. \%): $\mathrm{N} 4.78$ (5.52), S 5.94, Fe 69 mg/kg, Na $152 \mathrm{mg} / \mathrm{kg}$. Polypyrrole content (calculated from elemental analysis): $23 \% . \mathrm{d}=$ $40 \mathrm{~nm}$ (average particle diameter in TEM for native dispersion). DC conductivity of compressed powder (four-point measurement): $0.2 \mathrm{~S} / \mathrm{cm}$.

The black powder was re-dispersible in water (and also in some organic solvents like $\mathrm{N}, \mathrm{N}$-diemthyl-acetamide, DMA) to obtain dispersions with a solid content between 2 and $4 \%$.

\subsection{Synthesis of Polypyrrole-coated Core/shell Nanoparticles CP2 (Polypyrrole Content: 11\%)}

In analogy to CP1, $30 \mathrm{~g}$ of the core shell particle dispersion P2, corresponding to $2.31 \mathrm{~g}$ solid material, was diluted with water $(100 \mathrm{ml})$, degassed and purged with Ar. Pyrrole (0.305 g, $4.56 \mathrm{mmol}$ ) was added and the mixture stirred. Iron(III) tosylate-hexahydrate $(7.1 \mathrm{~g}, 10.48 \mathrm{mmol})$ dissolved in water $(30 \mathrm{ml})$ and degassed was continuously added during $30 \mathrm{~min}$. Stirring was continued for another $2 \mathrm{~h}$ at r.t.

Purification and work-up (as above): i) UF in VivaFlow ${ }^{\circledR}$ cell with polyethersulfone membrane, total permeate quantity: 3 $\times 275 \mathrm{ml}$. ii) Removal of iron salts: Oxidation of all $\mathrm{Fe}$ (II) to $\mathrm{Fe}(\mathrm{III})$ by addition of $\mathrm{H}_{2} \mathrm{O}_{2}(30 \%, 0.12 \mathrm{~g})$ diluted in water $(10$ $\mathrm{ml})$, stirring $1 \mathrm{~h}$ at r.t., followed by addition of a $0.1 \mathrm{M}$ solution of ethylenediaminetetraacetic acid disodium salt dihydrate (EDTA, $7 \mathrm{ml}$ ), stirring for $45 \mathrm{~min}$ and UF in a VivaFlow ${ }^{\circledR}$ cell, total permeate quantity: $3 \times 275 \mathrm{ml}$. iii) Ion exchange: Column with acidic $\left(\mathrm{H}^{+}\right)$Amberlite 120 resin $(150$ $\mathrm{ml}$ ) with a flow of $1-2 \mathrm{ml} / \mathrm{min}$, followed by re-concentration of the dispersion by UF to a solid content of $4.7 \%$.

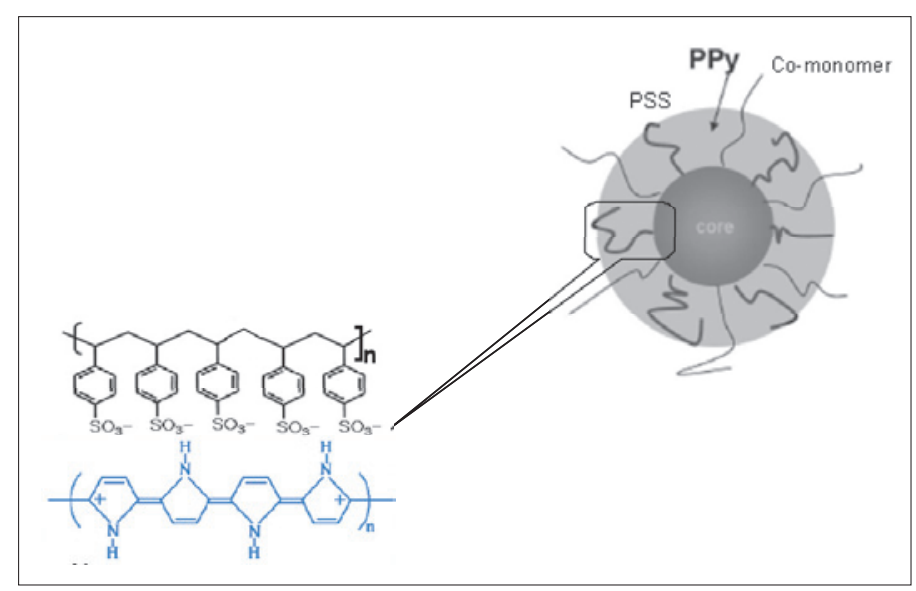

Fig. 2. Basic structure of the polypyrrole (PPy) coated core/ shell nanoparticles, containing polystyrene-sulfonate (PSS) and other comonomers in the shell ('corona').

Elemental analysis freeze-dried sample, found \%: N 2.29, S 5.96, Fe $17 \mathrm{mg} / \mathrm{kg}$, $\mathrm{Na} 194 \mathrm{mg} / \mathrm{kg}$. Polypyrrole content (calculated from elemental analysis): $10.96 \%$. d $=40 \mathrm{~nm}$ (average particle diameter in TEM for native dispersion).

The black powder was re-dispersed in water to obtain a dispersion of $3 \%$. It is also re-dispersible in N,N-dimethyl-acetamide (DMA).

\subsection{Synthesis of Polypyrrole-coat- ed Core/shell Nanoparticles CP3 (Polypyrrole Content: 6.4\%)}

In analogy to CP1, $40 \mathrm{~g}$ of the core shell particle dispersion of $\mathbf{P} \mathbf{2}$, corresponding to $3.09 \mathrm{~g}$ solid material, was diluted with water $(100 \mathrm{ml})$, degassed and purged with Ar. Pyrrole $(0.208 \mathrm{~g}, 3.10 \mathrm{mmol})$ was added and the mixture stirred under $\mathrm{Ar}$ at r.t. Iron(III)tosylate-hexahydrate $(4.83 \mathrm{~g}$, $7.13 \mathrm{mmol}$ ), dissolved in degassed water $(30 \mathrm{ml})$ was continuously added under Ar with a pump during $30 \mathrm{~min}$. Stirring was continued for another $2 \mathrm{~h}$ at r.t.

Purification and work-up (as for CP1): i) UF in VivaFlow ${ }^{\circledR}$ cell with polyethersulfone membrane, total permeate quantity: 3 $\times 300 \mathrm{ml}$. ii) Removal of iron salts: Oxydation of all $\mathrm{Fe}$ (II) to $\mathrm{Fe}$ (III) by addition of $\mathrm{H}_{2} \mathrm{O}_{2}(30 \%, 0.12 \mathrm{~g})$, diluted in water $(10$ $\mathrm{ml})$, stirring $1 \mathrm{~h}$ at r.t. followed by the addition of a $0.1 \mathrm{M}$ solution of EDTA $(7 \mathrm{ml})$, stirring for $45 \mathrm{~min}$ and UF in VivaFlow ${ }^{\circledR}$ cells, total permeate quantity: $3 \times 300 \mathrm{ml}$. iii) Ion exchange: Column with acidic $\left(\mathrm{H}^{+}\right)$ Amberlite 120 resin $(150 \mathrm{ml})$, flow of $1-2$ $\mathrm{ml} / \mathrm{min}$, followed by re-concentration of the dispersion by UF to a solid content of $4.7 \%$.

Elemental analysis of freeze-dried sample, found \%: N 1.33, S 6.59, Fe 75 $\mathrm{mg} / \mathrm{kg}$, Na $200 \mathrm{mg} / \mathrm{kg}$. Polypyrrole content (calculated from elemental analysis): $6.4 \% . \mathrm{d}=40 \mathrm{~nm}$ (average particle diameter in TEM for native dispersion).

The black powder is re-dispersed in water to obtain a dispersion of $3 \%$; $\mathrm{pH}=$ 1.5 .

\section{Results and Discussion}

\subsection{General Remarks}

Re-dispersible, printable conductive nanoparticles for applications in electronics (e.g. hole injection layers, smoothening layers, transparent conductive layers in $e . g$. OLEDs, solar cells, sensors and capacitors) were the main focus of this project. The basic target structure is shown in Fig. 2 with a soft core (styrene/acrylate) and an anionic shell (p-styrene-sulfonate (PSS) copolymer) which is called 'corona'. Polypyrrole (PPy) as conductive layer was deposited onto this shell by oxidative polymerization in aqueous dispersion.

\subsection{Synthesis of the Core (P1) and the Core/shell Nanoparticles (P2)}

Particles with a soft core based on styrene (S, 42\%), n-butyl acrylate (BA, 50\%) and allyl-methacrylate (ALMA, 8\%) were synthesized by monomer starved seeded emulsion polymerization according to the protocols of Sajjadi.[6] The composition was optimized previously in order to get a good copolymerization behavior and a low glass transition temperature $\left(\mathrm{T}_{\mathrm{g}}=30{ }^{\circ} \mathrm{C}\right.$ in this case) which would facilitate packing and coalescence of the particles upon annealing later on. We developed a new synthesis for the anionic shell and its covalent attachment to the core:[7] A mixture (50/50 by weight) of BA/p-divinyl benzene (DVB) was copolymerized onto the core, giving a large amount of free vinyl groups (from DVB) on the surface which serve as anchoring groups for the co-monomer mixture containing sodium-p-styrene sulfonate (SS). The synthesis of this 'corona' by emulsion polymerization with KPS as initiator is shown in Scheme 1 (see also experimental part of P2). It consists of SS (60\%), poly(ethylene glycol) methylether acrylate (M-PEG-A, 19.5\%), ethoxyethylmethacrylate (EEMA, 19.5\%) and a small amount of the crosslinker ethylene glycol dimethacrylate (EDMA, 1\%) grafted onto the core. 


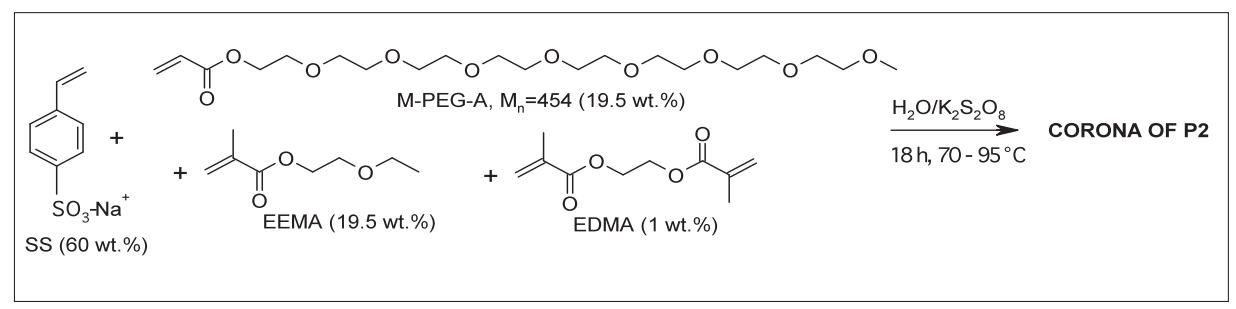

Scheme 1. Synthesis of anionic shell (corona) of P2, consisting mainly of SS, M-PEG-A and EEMA.

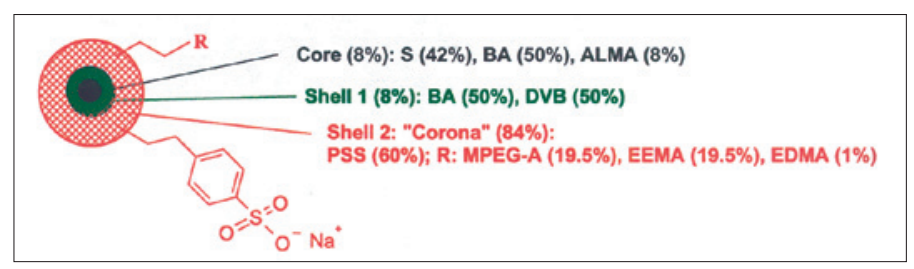

Fig. 3. Composition of P2. The weight ratio of core/anionic shell (corona) is 1:5.4

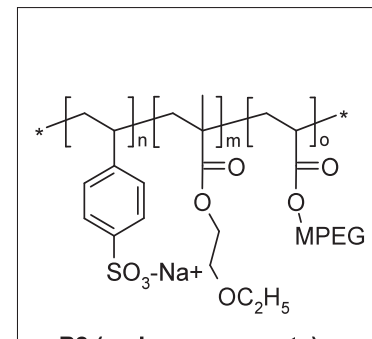

P2 (main components)

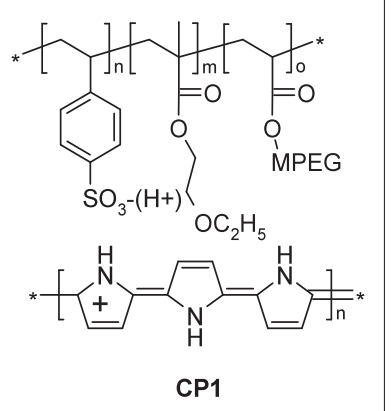

Scheme 2. Synthesis of CP1 by deposition of PPy onto the corona of P2 by oxidative polymerization of pyrrole (Py) with $\mathrm{Fe}(\mathrm{tos})_{3}$.

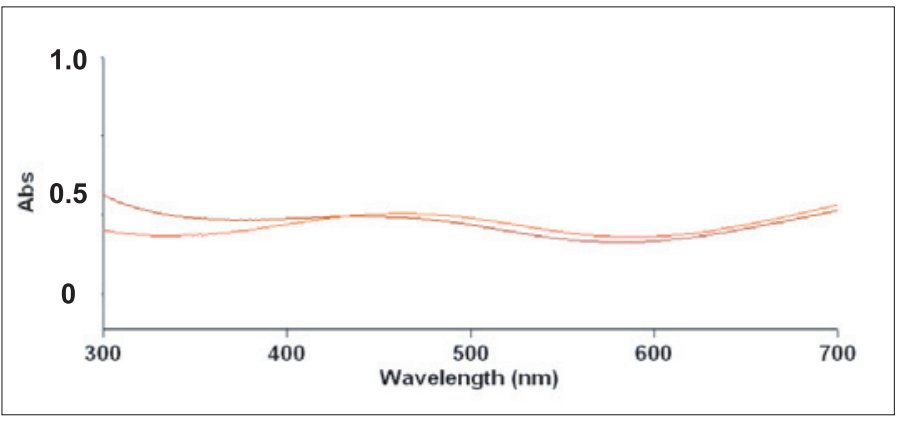

Fig. 4. UV-VIS spectrum: red curve corresponds to the ultra-filtrated aqueous dispersion of CP1, concentration: $0.0042 \%$. The brown curve: corresponds to freeze-dried and in water re-dispersed powder of CP1 at the same concentration.
A schematic drawing and the overall composition of the core/shell particle P2 is given in Fig. 3. The composition, in particular the PSS content was confirmed by elemental analysis.

\subsection{Synthesis of the Conductive Core/shell Nanoparticles (CP1- CP3)}

The polypyrrole (PPy) coating of the core/shell particle $\mathbf{P} 2$ was made by oxidative polymerization of different amounts of pyrrole by continuous addition of $\mathrm{Fe}^{\mathrm{III}}$ (tos) as oxidant to obtain CP1-CP3 (Scheme 2). The products were purified by UF and ion exchange and than concentrated to the desired value $(2-3 \%)$ by UF. Part of the dispersions was freeze-dried to obtain solid the four-point method. CP1, with the highest PPy content, showed a conductivity of ca. $0.2 \mathrm{~S} / \mathrm{cm}$, whereas the conductivity of the two others was below the measurement range of the device $(0.1 \mathrm{~S} / \mathrm{cm})$. More accurate DC conductivity measurements were made by temperature-dependent dielectric spectroscopy. Fig. 5 shows the results for all three samples and the comparison with PEDOT:PSS 'Al 4083'. As expected, the conductivity depends on the PPy content and increases with temperature. The result for CP1 at $298 \mathrm{~K}$ corresponds quite well to the value obtained by the four-point method, although a bit lower. All CP samples show a considerably higher DC conductivity than PEDOT:PSS. Especially interesting is the comparison of CP2 with Al 4083, since its PPy-content (11\%) corresponds almost exactly to the PEDOT content of $\mathrm{Al}$ $4083(11.3 \%)$ but shows a more than one decade higher conductivity. The core/shell morphology of our samples could be the reason since the PPy is probably homogeneously distributed onto the shell and forms a percolating network with higher apparent PPy concentration since the nonconductive core does not count (Fig. 6b). Further investigations showed that at $\phi_{\mathrm{PPy}}<0.52$ $\left(\phi_{\mathrm{PPy}}=\right.$ volume fraction of PPy $)$, the ionic conductivity (mainly $\mathrm{H}^{+}$and $\mathrm{Na}^{+}$) plays a significant role in the charge transfer (Fig. 6a). This is the case for CP3 (PPy-content: $6.4 \%$ ), showing a qualitatively different conductivity vs. temperature curve (Fig. 5). At $\phi_{\mathrm{PPy}}>0.52$ (PPy-content: $>7 \%$ ), the electronic conductivity dominates (Fig. $6 \mathrm{~b})$, i.e. the total conductivity is governed by the conjugated PPy bonds.

\subsection{AFM (and KPFM) Measure- ments on Spin-coated Films}

Fig. 7 displays as an example, the AFM results of a thin film $(80 \mathrm{~nm})$ made by spincoating of an aqueous dispersion of CP2, before and after annealing for $10 \mathrm{~min}$ at $180{ }^{\circ} \mathrm{C}$. Note that the particles are able to form a continuous film, even at room temperature without annealing and the film roughness did not change very much after annealing. Table 2 lists the $\mathrm{R}$-values of the conductive nanoparticles CP1-CP3 and shows that this is the case for all investigated samples. The surface roughness decreases with lower PPy content and is - in any case - considerably lower than the film thickness. This is surprising since all particles have a diameter (d) of $c a .40$ $\mathrm{nm}$, determined by TEM. We think that the high amount of polymerized M-PEG-A in the shell, solvent swelling and compaction during spin-coating and film formation, gives a large smoothing effect. However, in comparison with PEDOT:PSS, having a film roughness $<1 \mathrm{~nm}$ (before and after annealing), film roughness is considerably higher for these core/shell particles. 


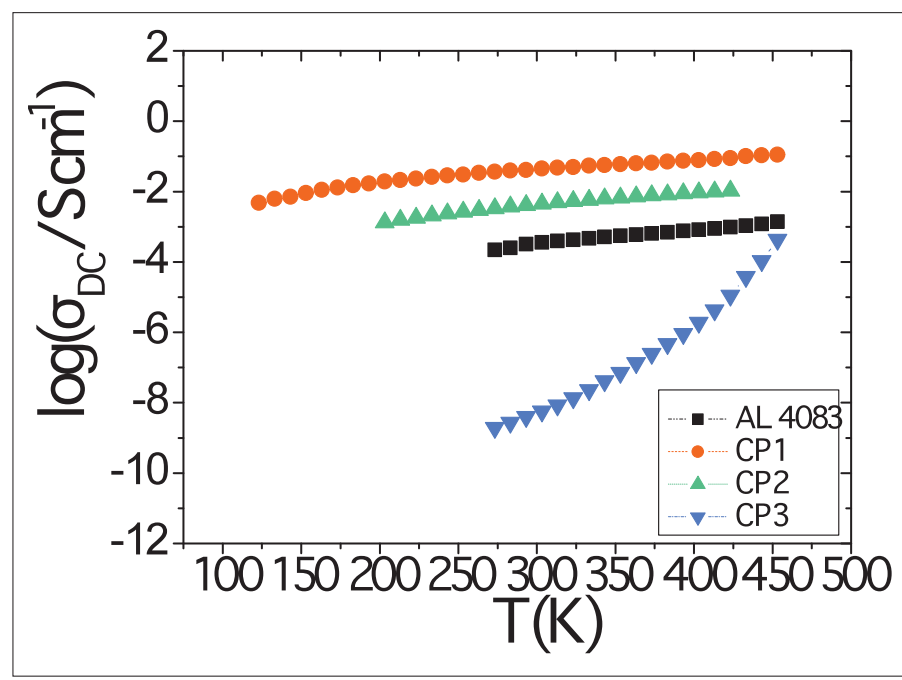

Fig. 5. DC

conductivities vs. temperature of PPy-coated core/ shell nanoparticles as compared to $\mathrm{AL}$ 4083 (PEDOT/PSS with $11.3 \%$ PEDOT content), black squares. Red points: CP1 (23\% PPy); green triangles: CP2 (11\% PPy); blue triangles: CP3 (6.4\% PPy).

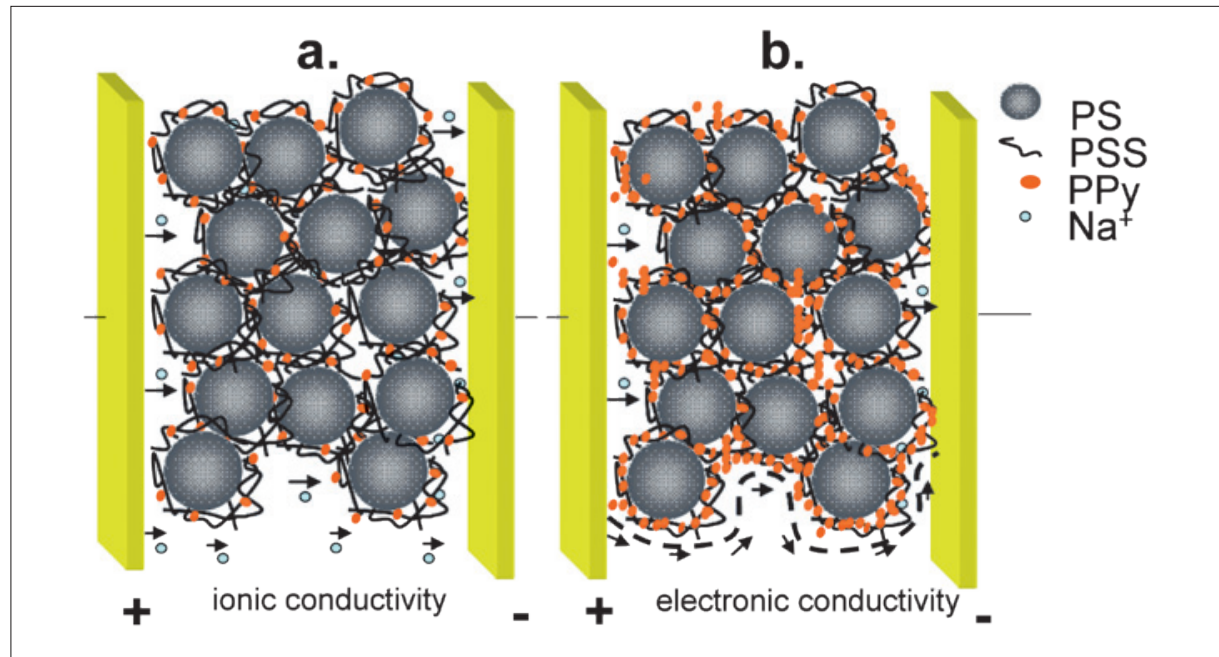

Fig. 6. Schematic picture of the proposed charge transfer mechanism of the PPy-coated core/ shell nanoparticles at $\mathrm{T}<\mathrm{T}_{\mathrm{g}}$. At low PPy content in the shell, the overall conductivity is governed by the ion mobility (Fig. 6a). In contrast, at higher PPy content, the overall conductivity is governed by the electronic conductivity (conjugated PPy bonds, Fig. 6b).

We also determined the work function for CP2 by Kelvin probe force microscopy (KPFM) and obtained $5.25 \pm 0.05$ $\mathrm{eV}$ after annealing, almost identical to the work function of the standard material PEDOT:PSS 'AL 4083' (5.3 eV after annealing).

\subsection{Absorption and Transmission of Dispersions and Spin-coated Films}

Fig. 8a shows some UV-VIS-NIR absorption spectra of 0.009 wt.\% dispersions of CP1-CP3, as compared to AL 4083. Note that this concentration corresponds to a solid layer thickness of $\mathrm{d}=900 \mathrm{~nm}$. PEDOT:PSS has an absorbance of $c a$. A $=0.1$ at $\lambda=400-500 \mathrm{~nm}$ (same concentration), considerably lower than all $\mathbf{C P}$ samples, even CP3 with a PPy content of only $6.4 \%$.

Fig. $8 \mathrm{~b}$ shows the transmission of real films, thickness $80 \mathrm{~nm}$, spin-coated and annealed on a glass plates. The PPy content of CP2 is almost the same as the PEDOT content of AL 4083 but has a significant lower visible transmission. In CP3, with only $6.4 \%$ PPy content, the transmission in the wavelength regime between $400-650$ $\mathrm{nm}$ is lower but reaches that of AL 4083 at higher wavelength. Therefore, one can say that polymers/particles containing PEDOT have a significantly higher transmission than those with PPy at the same wt.\% concentration of conductive polymer. This holds also if the values are calculated in mol\%, instead of wt.\%.

\subsection{Thermal Stability of PPy-coated Core/shell Nanoparticles}

Since the hole injection layer in OLED devices is annealed at $180-200{ }^{\circ} \mathrm{C}$ for 10 min, the thermal stability could be a critical issue. Therefore, an extended TGA/ MS/IR investigation on the freeze-dried samples was performed.

All particle types showed a similar thermal stability and there was no differ-

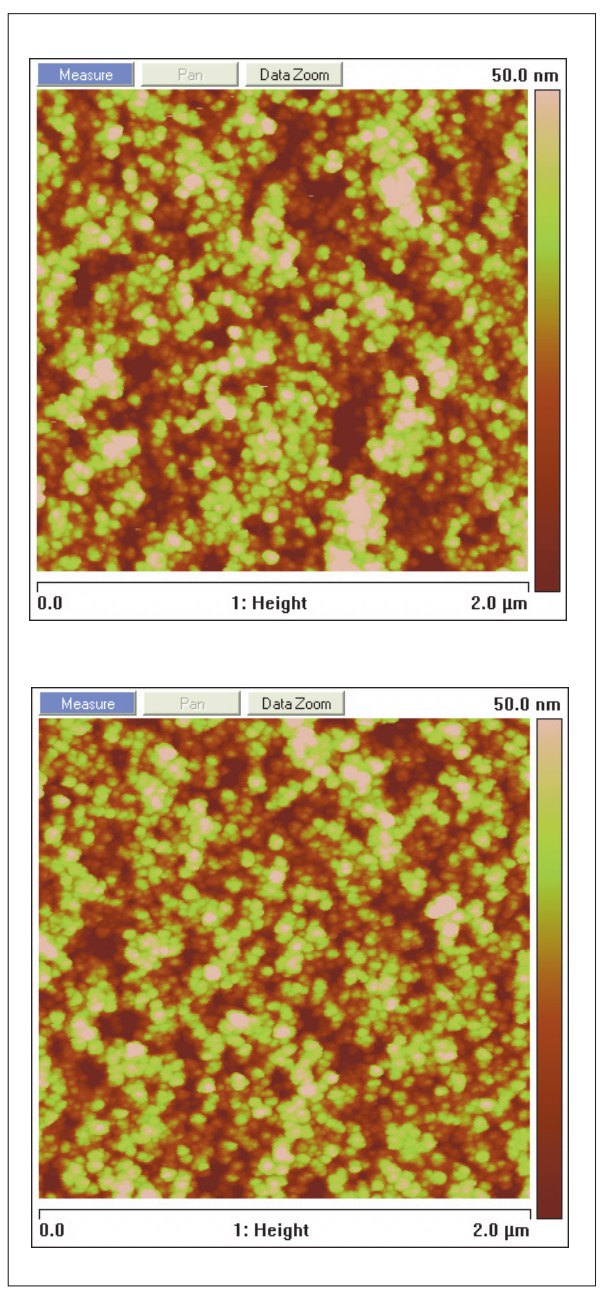

Fig. 7. AFM-images of a spin-coated film made from an aqueous dispersion (2\%) of CP2 on a silicon wafer, before (top image) and after annealing for $10 \mathrm{~min}$ at $180^{\circ} \mathrm{C}$ (bottom image). X-y scale: $2 \mu \mathrm{m}$, z-scale: $50 \mathrm{~nm}$. $\mathrm{R}$ before annealing: $14 \mathrm{~nm}$; after annealing: $12 \mathrm{~nm}$ (see Table 2).

Table 2. Mean square roughness values $(R)$ from AFM images of spin-coated films of CP1CP3 before and after annealing for $10 \mathrm{~min}$. at $180^{\circ} \mathrm{C}$

\begin{tabular}{lll|}
\hline Sample No. & $\begin{array}{l}\mathrm{R}_{\mathrm{q}} \text { before } \\
\text { annealing } \\
{[\mathrm{nm}]}\end{array}$ & $\begin{array}{l}\mathrm{R}_{\mathrm{q}} \text { after } \\
\text { annealing } \\
{[\mathrm{nm}]}\end{array}$ \\
\hline CP1 & 16 & $15^{\mathrm{a}}$ \\
CP2 & 14 & 12 \\
CP3 & 9 & 8 \\
For & $<1$ & $<1$ \\
Comparison: & & \\
'Al 4083' & & \\
\hline aannealing at $200{ }^{\circ} \mathrm{C}$. &
\end{tabular}

ence if measured under Ar or air. Up to T $=300{ }^{\circ} \mathrm{C}$ only water vapour $(\mathrm{ca} .3 .5 \%$ up to $200{ }^{\circ} \mathrm{C}$ and $\mathrm{ca} .10 \%$ up to $300{ }^{\circ} \mathrm{C}$ ) was released. At temperatures above $300{ }^{\circ} \mathrm{C}$, the sulfonate group decomposes ( $\mathrm{SO}$ and $\mathrm{SO}_{2}$ residues in $\mathrm{MS}$ ). 


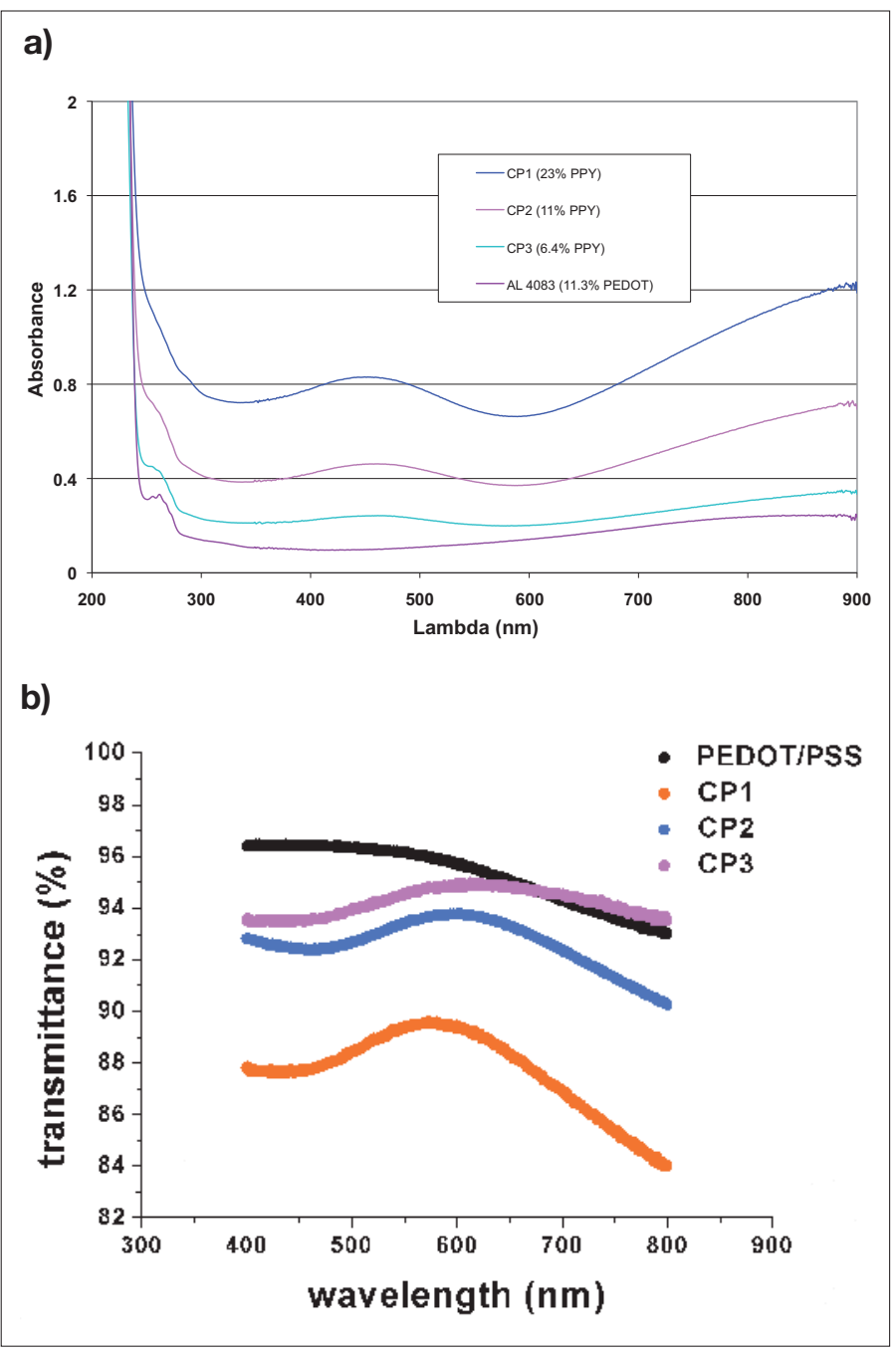

Fig. 8. a) UV-VIS-NIR absorption spectra of aqueous dispersions (always $0.009 \%$ ) of CP1-CP3 (decreasing PPy content), as compared to AL 4083 (PEDOT/PSS); b) Transmission of a $80 \mathrm{~nm}$ spin coated film, annealed 10 $\min$ at $180^{\circ} \mathrm{C}$. Core/ shell particles CP1CP3 (PPy content decreasing from 23 to 6.4 wt.\%), compared with the PEDOT/ PSS (AL 4083, 11.3\% PEDOT) system used for OLEDs. b)

\subsection{OLED Test Results}

Table 1 shows test results of standard OLED devices (SY as emitter) made from the aqueous nanoparticle dispersions CP1 and CP2, as compared to the standard material AL 4083. No attempts were made to optimize the device to these non-standard materials. The IV-curves, luminance, efficiency and lifetime of the devices made with CP1 and CP2 reach almost the state of the art. Note that the OLED device with CP1, having the highest PPy content, exhibits a lower forward leaking current density (current density at lower than the turnon voltage, $<2 \mathrm{~V}$ ) which could be helpful in preventing the crosstalk in passive matrix polymer LED displays. ${ }^{[9]}$ Since CP1 and CP2 have a considerably lower transmission than AL 4083 at the same film thickness (Fig. 8b), CP3 was also tested. However, it showed IV-curves with enormous scattering (Fig. 9). The low overall conductivity, dominated by ions and not electrons in the case of CP3 (as already shown in Fig. 5), might be the reason. Subsequent OLED tests showed that the influence of film thickness and roughness is negligible in the range of $\mathrm{d}=50-100 \mathrm{~nm}$ and $<15 \mathrm{~nm}$ roughness.

\section{Conclusions}

The easy and straightforward synthesis of spherical nanoparticles with a corona of a copolymer between p-styrene sulfonate and M-PEG-A, grafted to a soft core, is described. The polyelectrolyte shell of these particles serves as template for the deposition of various amounts of polypyrrole to form conductive nanoparticles. Films obtained by spin-coating of the dispersions are relatively smooth, even without annealing. They show a high conductivity and a good performance if used as hole injection/ smoothing layer in a standard fluorescent OLED device.

Due to their electrosteric stabilization, the particles can be isolated as dry powder, stored and re-dispersed in water and some organic solvents. This opens up new horizons in optoelectronics where high conductivity, re-dispersibility and film smoothness is required for components to be useful in a broad range of different formulations.

\section{Acknowledgements}

We thank P. Fux for the TGA/MS/IR measurements, P. van der Schaaf for his input

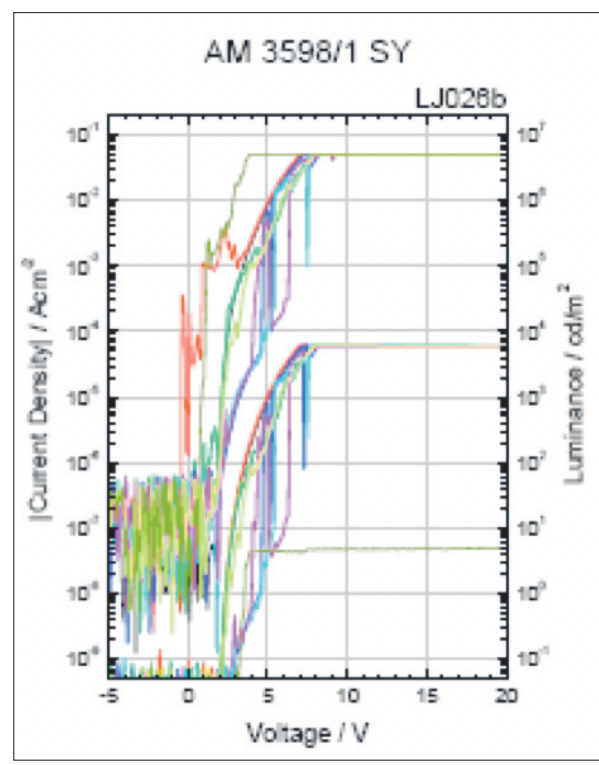

Fig. 9. IV-curve of OLED devices (represented by different colors) made with CP3. Left (upper curve): Current density $\left[\mathrm{A} / \mathrm{cm}^{2}\right]$; right (lower curve): Luminance $\left[\mathrm{cd} / \mathrm{m}^{2}\right]$; horizontal axis: Voltage [V].

and interesting discussions and W. Rutsch for reading the manuscript and corrections.

Received: December 18, 2009

[1] Bolto and Weiss and co-workers reported highconductivity (up to $1 \mathrm{~S} / \mathrm{cm}$ ) in iodine-doped oxidized polypyrrole already in 1963 (!): B. A. Bolto, D. E. Weiss, Aust. J. Chem. 1963, 16, 1076.

[2] W. Wernet, Syn. Lett. 1991, 41-43, 843. He reported film conductivities up to $17 \mathrm{~S} / \mathrm{cm}$ !

[3] a) A. Yassar, J. Roncali, F. Garnier, Polym Commun. 1987, 28, 103; b) S. P. Armes, S. Gottesfeld, J. G. Beery, F. Garzon, S. F. Agnew, Polymer 1991, 32, 2325; c) C.-F. Liu, T. Maruyama, T. Yamamoto, Polym. J. 1993, 25, 363; d) M. A. Khan, S. P. Armes, Adv. Mater. 2000, 12, 671; e) F. M. Huijs, F. F. Vercauteren, B. de Ruiter, D. Kalicharan, G. Hadziioannou, Synthetic Metals 1999, 102, 1151.

[4] J. Wang, L. Sun, K. Mpoukouvalas, K. Lienkamp, I. Lieberwirth, B. Fassbender, E. Bonaccurso, G Brunklaus, A. Muehlebach, T. Beierlein, R. Tilch, H. J. Butt, G. Wegner, Adv. Mater. 2009, 21, 1137.

[5] J. Wang, L. Sun, K. Mpoukouvalas, B. Fassbender, E. Bonaccurso, G. Brunklaus, A Muehlebach, T. Beierlein, R. Tilch, H.-J. Butt, G. Wegner, Macromol. Chem. Phys 2009, 210, 1504.

[6] S. Sajjadi, J. Polym. Sci., Polym. Chem. Ed. 2001 39, 3940.

[7] At the beginning of the project, we synthesized the anionic shell by copolymerizing 4-vinylbenzene sulfonate ethylester with other co-monomers and a crosslinker, followed by subsequent hydrolysis of the ester with aqueous sodium hydroxide, see Ref. [4]. Since the ethylester of p-styrene sulfonate is not commercially available and it's synthesis via the silver sulfonate salt very expensive, we developed our own synthesis (two steps via the acid chloride). In this way, we could not only isolate the ethyl ester but also the propyl-, isopropyl-, butyl- and hexyl-esters in excellent yields. However, later on, we discovered by comparing the sulfur content from elemental analysis of the freeze-dried powders with the calculated values, that most of the poly(sodium-p-styrene sulfonate) (PSS) copolymer in the shell was lost upon hydrolysis.

[8] F. Rime, A. Mühlebach, unpublished results.

[9] D. Braun, Synth. Met. 1998, 92, 107. 